\title{
On the spider parasitoids Polysphincta longa Kasparyan and $P$. boops Tschek (Hymenoptera, Ichneumonidae, Pimplinae), with the first host records of $P$. longa
}

\author{
Niclas R. Fritzén ${ }^{1,2}$, Mark R. Shaw ${ }^{3}$ \\ I Zoological Museum, University of Turku, FI-20014 Turku, Finland 2 Klemetsögatan 7 B7, FI-65100 Vasa, \\ Finland 3 Hon. Research Associate, National Museums of Scotland, Edinburgh EH1 IJF, U.K. \\ Corresponding author: Niclas R. Fritzén (nrfritzen@gmail.com) \\ Academic editor: Gavin Broad | Received 25 March 2014 | Accepted 20 June 2014 | Published 26 September 2014 \\ http://zoobank.org/EBE387CC-FAD2-4BDC-8F86-8C94BB0DA161 \\ Citation: Fritzén NR, Shaw MR (2014) On the spider parasitoids Polysphincta longa Kasparyan and P. boops Tschek \\ (Hymenoptera, Ichneumonidae, Pimplinae), with the first host records of P. longa. Journal of Hymenoptera Research 39: \\ 71-82. doi: 10.3897/JHR.39.7591
}

\begin{abstract}
The rarely recorded Polysphincta longa is probably widely overlooked in Europe as a result of confusion with the morphologically similar $P$. boops. Characters for the separation of these species are given, and host and distribution records, largely based on recent fieldwork, are presented. Araneus angulatus is shown to be the hitherto unknown host of $P$. longa, while all rearing records for $P$. boops are from Araniella species. $P$. longa is reported as new to the fauna of the United Kingdom and $P$. boops as new to Estonia.
\end{abstract}

\section{Keywords}

Araniella, Araneus angulatus, cocoon, Poland, Finland, rearing

\section{Introduction}

The description of Polysphincta longa Kasparyan, 1976 was based on 10 females from Azerbaijan (holotype), Armenia and Primorsky Krai (Kasparyan 1976). The original description (Kasparyan 1976) and the only keys including this species (Kasparyan 1981, Kasparyan and Khalaim 2007) are in the Russian language, and the species has 
not been treated in any other work on European species. It has subsequently been recorded in Germany (Walter 1991, Schmidt and Zmudzinski 2003), Bulgaria (Ivanov 2002) and Poland (Kasparyan and Khalaim 2007, Horstmann and Floren 2008). In the papers giving records from Bulgaria and Germany it is not indicated how the specimens were distinguished from the very similar $P$. boops Tschek, 1869 , nor is it stated that the records were the first for those countries, or indeed for Europe. The literature also seems to lack records of males of $P$. longa. Polysphincta boops is known to be a parasitoid of Araniella spp. (Hudson 1988, Jones 1988, Fitton et al. 1988, Shaw 1994) but the host of $P$. longa has hitherto been unknown (Yu et al. 2012).

The main purpose of this paper is to give diagnoses of $P$. boops and $P$. longa in English to facilitate the recognition of $P$. longa in Europe, as it seems to occur in large parts of central Europe but is apparently overlooked because of its similarity to P. boops. This is indicated by a misidentified 80 -year-old specimen in the collection of BMNH and the very few literature records of the species in Europe. Two males of $P$. longa are included in our material. We give new notes on the hosts of $P$. boops and present the first host records for P. longa.

\section{Material and methods}

The material examined is based on mainly reared specimens of $P$. boops in the collections of NRF from Finland and NMS from Britain, as well as some specimens collected within the Swedish Malaise trap project (SMTP). Apart from the paratype and a German and a British specimen in BMNH, the examined specimens of P. longa have been collected in Poland, either with yellow pan traps in Quercus canopy or on their hosts in spruce canopy.

The hosts of $P$. longa were immature and were determined by their overall habitus. The Araniella hosts of $P$. boops were determined based on their habitus and mainly to genus level only, but a single specimen was determined to species level based on its copulatory organ. Any uncertainty is indicated with a "?" in the material examined.

The measurements were made using an ocular micrometer with an accuracy of 0.1 $\mathrm{mm}$. Abbreviations used in the text: coll. refers to the date when the parasitised spider was collected; coc. refers to the date of finishing the construction of the cocoon; em. to the date of emergence.

Figures 1-5 were made using an Olympus E-520 DSLR attached to an Olympus SZX16 stereomicroscope and composed using CombineZM image stacking software at the Zoological Museum, University of Turku. Figures 6-8 were made with Olympus E-300 and E-3 DSLR with a twin flash.

Depositories: NRF $=$ Private collection of the first author, FI; NRM $=$ Swedish Museum of Natural History, Stockholm, SE; ZISP = Zoological Institute of the Russian Academy of Sciences, St. Petersburg, RU; NMS = National Museums of Scotland, Edinburgh, UK; BMNH = The Natural History Museum, London, UK; RJ = Private collection of Reijo Jussila, FI. 


\section{Species survey}

\section{Polysphincta longa Kasparyan, 1976}

Figures 1-3, 8

Material examined. AZERBAIJAN: Paratype + (ZISP) Kalaybugurt forest 22.vii.1971 (Kuslicky); POLAND: Białowieża, west of the village: $10^{\hat{N}}$ (NRF) $52.7128^{\circ} \mathrm{N} ; 23.7151^{\circ} \mathrm{E}$, old forest with Quercus, Betula, Fraxinus and sparse spruce trees (Picea abies), beaten from spruce branches, ex Araneus angulatus, coll. 9.vii.2010, coc. 12.vii.2010, em. 20.vii.2010 (N. R. Fritzén) (Figure 8); 1 q (NRF) $52.7190^{\circ} \mathrm{N}$; $23.7871^{\circ}$ E, old mixed forest with Picea abies, Quercus, Betula and Populus, beaten from spruce branches, ex Araneus angulatus, coll. 10.vii.2010, coc. 15.vii.2010, em. 24.vii.2010 (N. R. Fritzén) (Figure 1); $1 \overbrace{}^{\Uparrow}$ (NMS) Krotoszyn, yellow pan trap in Quercus canopy, vi.2009 (J. Hilszczanski); GERMANY: 1 ( (BMNH) labelled "59.101 Germany", "P. eximia", "Ruthe coll. 59.101", and "Polysphincta boops Tschek + , J. F. Perkins det ix-1934” (det. N. R. Fritzén 2013); WALES: 1 q (BMNH) Denbighshire SJ365548, Horsley Hall, beech log, 20.ix.2010 (J. B. Formstone) (det. G. R. Broad 2014, not examined by us).

Distribution. Azerbaijan, Armenia, Primorsky Krai, Poland, Germany, Bulgaria (Kasparyan 1976, Kasparyan and Khalaim 2007, Horstmann and Floren 2008, Walter 1991, Ivanov 2002) and United Kingdom (the present paper).

Biological notes. Koinobiont ectoparasitoid of Araneus angulatus Clerck, 1757. Both reared specimens were on juvenile hosts. Based on the collecting and rearing data the species is at least bivoltine, with one generation in June and a second one from late July. The larva is positioned in the typical Polysphincta manner, transversely at the anterior apex of the spider's opisthosoma just above the pedicel, with the anterior end moving laterally towards the posterior part of the opisthosoma while growing. Before their death the spiders did not spin any "death chamber" (see discussion) or any other distinctly modified web construction for the larva to cocoon in. Only some additional droplets and threads of silk were attached to the wall of the rearing vial onto which the larva attached when making its cocoon. The cocoon (Figure 8) is diaphanous, fulvous, and fusiform with an open and springy construction of irregular silk, and with a size of $11.8 \times 6.3 \mathrm{~mm}$ for the reared larger female. The species is arboreal, perhaps in long established forests.

\section{Polysphincta boops Tschek, 1869}

Figures 4-7

Material examined. FINLAND: $1 \hat{\jmath}$ (NRF) ex Araniella sp., Al, Sund, Kulla, open moist grassland, coll. vi.2003, (N. R. Fritzén); $1{ }^{\lambda}$ (NRF) ex Araniella sp., Al, Lemland, Jungfruskär (nature reserve), edge between spruce forest and seashore, coll. 26.v.2006, coc. 1.vi.2006, em. 11.vi.2006 (N. R. Fritzén); $1{ }^{\Uparrow}$ (NRF) ex Araniella sp., 


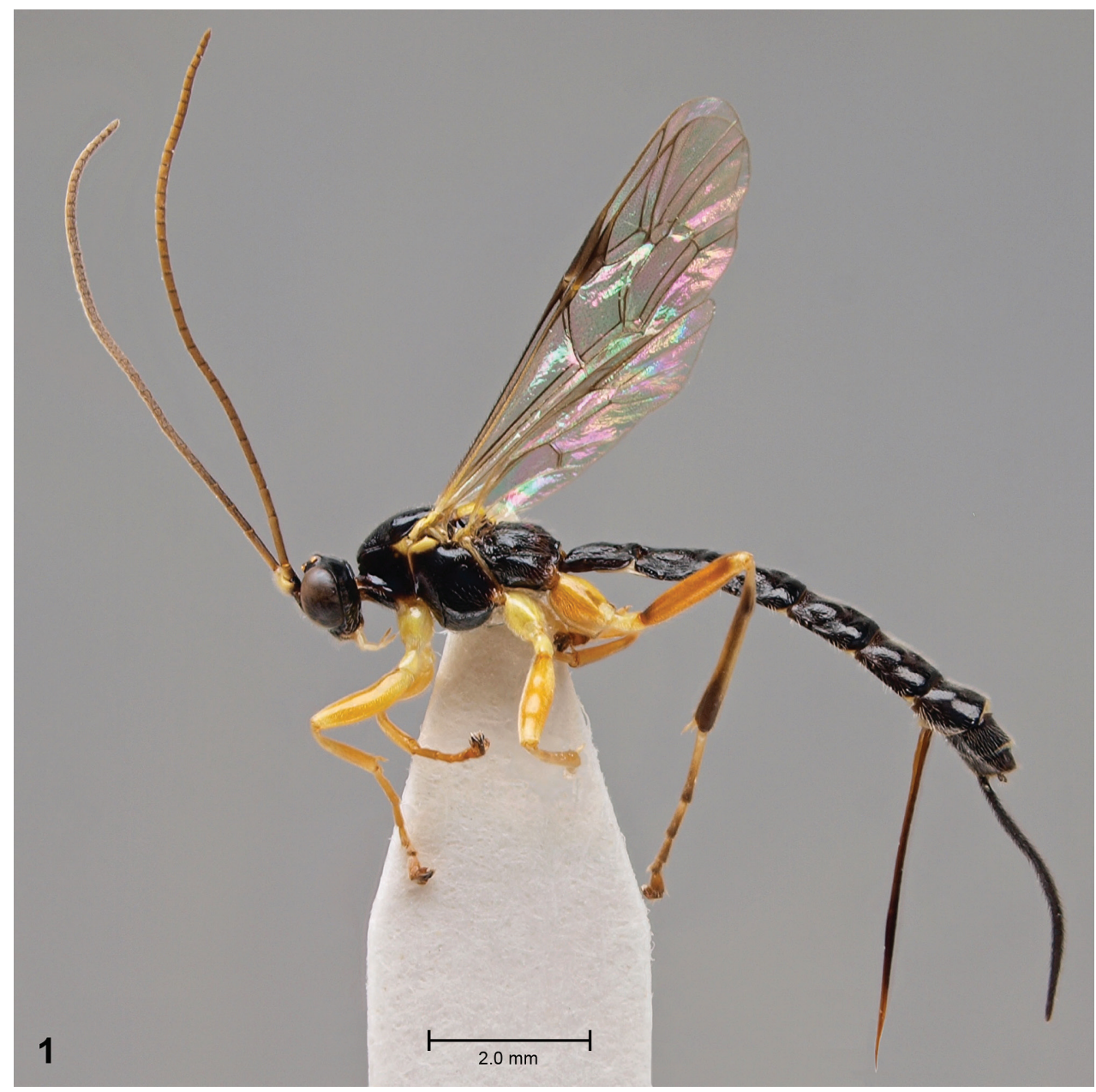

Figure I. Polysphincta longa, habitus in lateral view.

$A b$ : Kaarina, Kuusisto, garden close to forest, beaten from Abies sp., coll. 26.ix.2006, coc. 19.xi.2006, em. 30.xi.2006 (N. R. Fritzén) (Figure 7); $1 \delta^{\lambda}$ (NRF) ex Araniella sp., $A l$, Hammarland, Ängessjö (nature reserve), sweeping of vegetation at rich fen, coll. 19.v.2007, coc. 23.v.2007 (N. R. Fritzén); $1 \jmath^{\Uparrow}$ (NRF) ex Araniella sp., Ta, Lammi biol. st., mixed grove at lake shore, beaten from spruce, coll. 5.iv.2008, em. <6.v.2008 (I. Österblad); $1 \delta^{\Uparrow}$ (NRF) ex Araniella sp., Obu, Keminmaa, Helkkusenvaara, sweeping of Betula nana at edge of small open bog, coll. 3.vi.2007, 10.vi.2007, em. 20.vi.2007 (N. R. Fritzén) (Figure 6); $1 \hat{\jmath}$ (NRF) ex adult $ๆ$ Araniella cucurbitina, Ta, Iitti, Radansuu, in hotel room, coll. 5.vii.2010, coc. <10.vii.2010, em. - 17.vii.2010 (R. Pajarre); 19 (NRF) ex Araniella sp., N, Hangö, Tvärminne zool. st., in Artemisia vulgaris at open parking place, coll. 24.vii.2007, coc. 27.vii.2008, em. viii.2008 (I. Österblad); SWEDEN: $1 q$ (NRM) Sm, Nybro, Bäckebo, Grytsjön (nature reserve), Malaise trap 


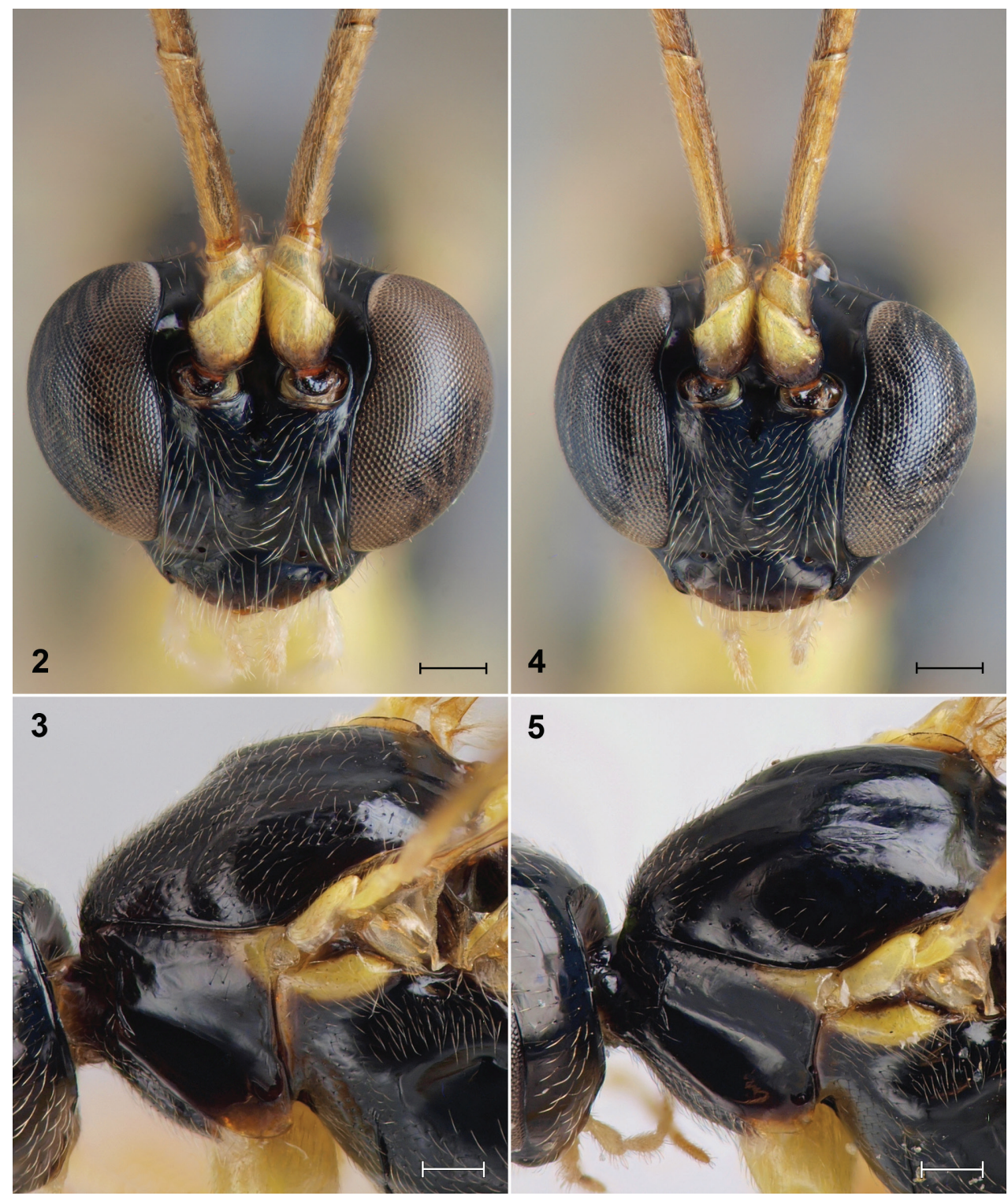

Figures 2-5. Head in anterior view $(\mathbf{2}, \mathbf{4})$ and anterior part of mesosoma in dorsolateral view $(\mathbf{3}, \mathbf{5})$ of Polysphincta longa (2-3) and P. boops (4-5). Scale bars $0.2 \mathrm{~mm}$.

in old moist haymaking meadow at forest edge (=Trap ID 1001), 12.ix-10.x.2005 (=coll. event ID 1366) (SMTP); 1 (NRM) Sm, Gränna, Lönnemålen, Malaise trap in Norway spruce forest with big harvested ashes (= Trap ID 17), 13.vii-20.viii.2004 (=coll. event ID 968) (SMTP); $1 \sigma^{\Uparrow}$ (NRM) Bh, Stenungsund, Kolhättan, Malaise trap in broad-leaved deciduous forest (=Trap ID 31), 29.vi-14.vii.2004 (=coll. event ID 1059) (SMTP); $1 \hat{\jmath}$ (NRF) ex Araniella sp. Hls, Söderhamn, Sphagnum-bog, coll. 


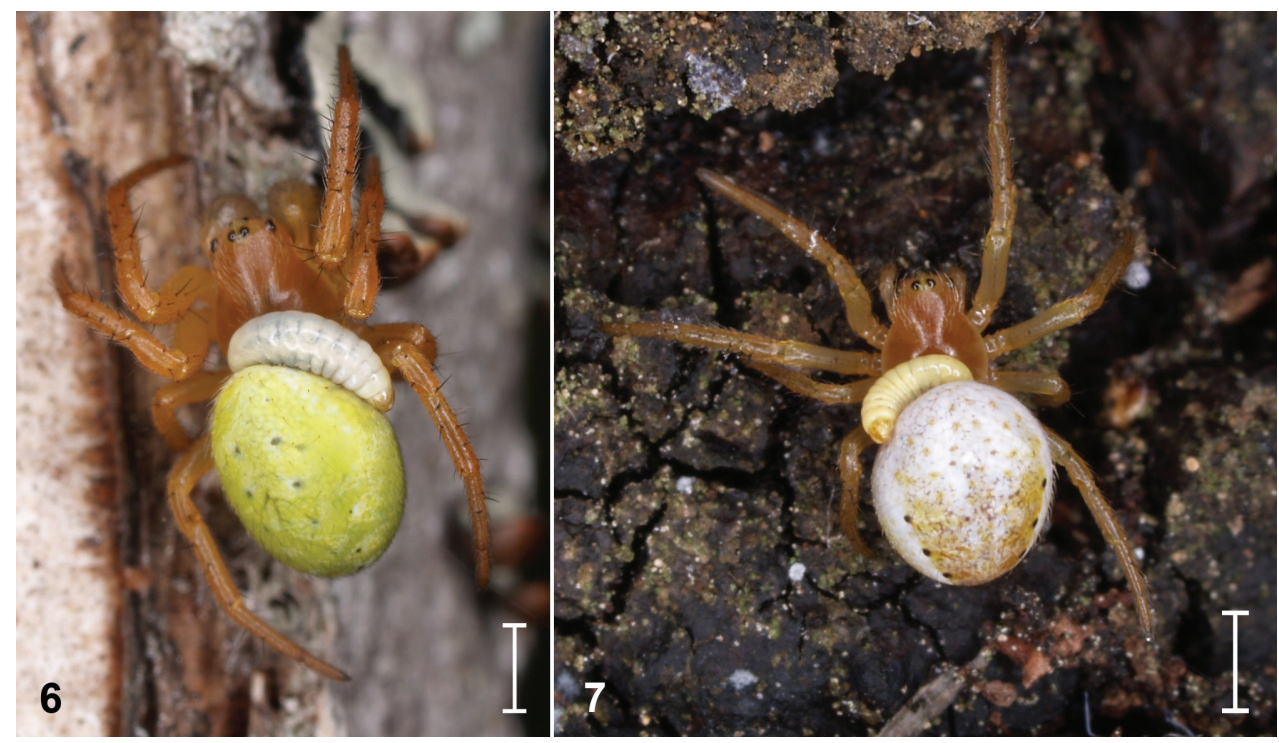

Figures 6-7. Araniella sp. with larva of Polysphincta boops. Scale bars $1 \mathrm{~mm}$.

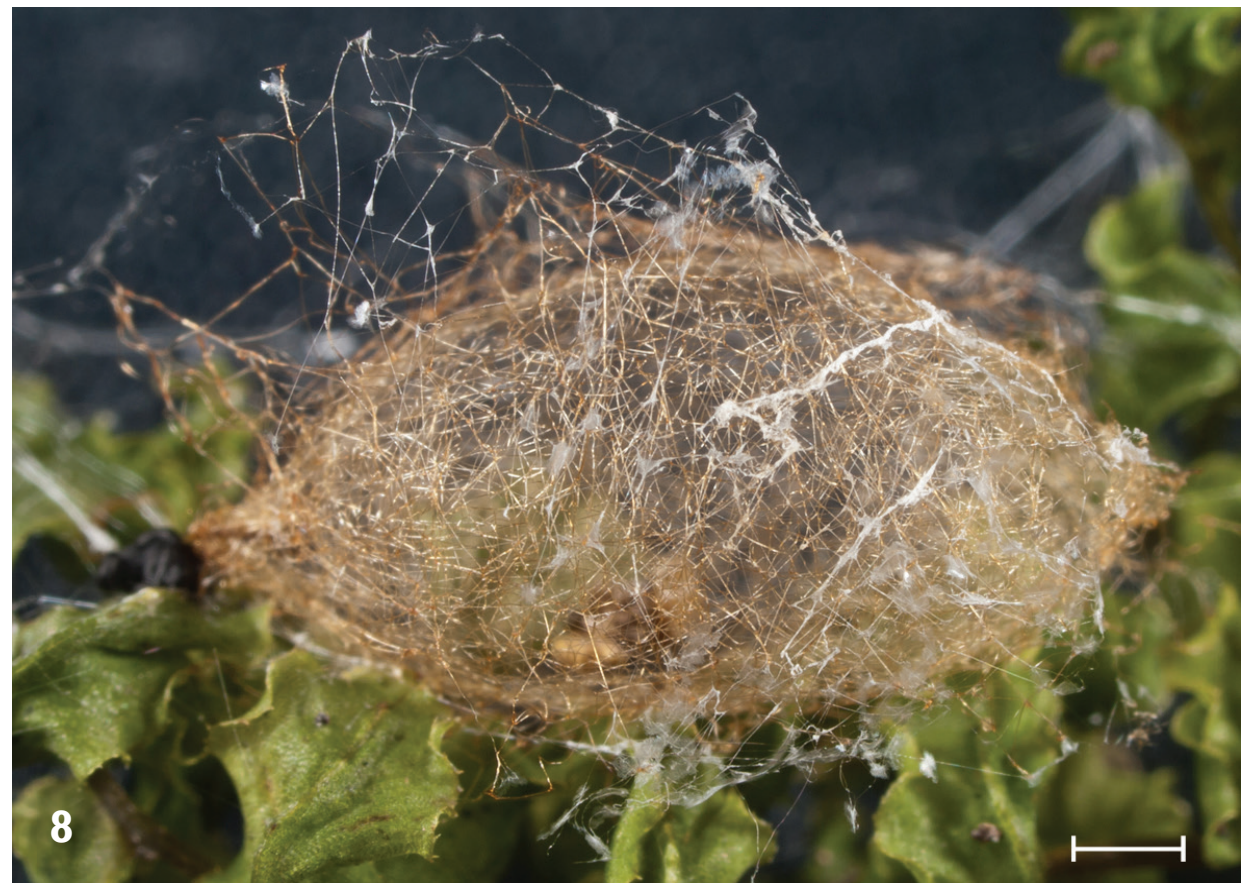

Figure 8. Cocoon of Polysphincta longa. Scale bar $1 \mathrm{~mm}$.

26.iv.2009 (I. Österblad); POLAND: 29 (NMS) Biebrza National Park, Kopciowe, Yellow pan, vii-ix.2002 (J. Hilszczanski); ENGLAND: Surrey, Box Hill, TQ 1852: 1 ㅇ (NMS) ex Araniella [?] cucurbitina, coll. 25.vi.1989, coc. ca 4.vii.1989, em.16. 
vii.1989 (M. Askins); 10ิ (NMS) ex Araniella sp., Taxus, coll. 25.vi.1989, em. vii/ viii.1989 (E. E. Emmett); 1ठ (NMS) ex Araniella sp., bushes, coll. 2.vii.1989, em 1989 (F. M. Murphy); 1ठ (NMS) ex Araniella [?]cucurbitina, Devon, Horrobridge, Denham Wood, SX 475674, coll. 2.v.1990, em. 1990 (P. Smithers); Cumbria, Whitbarrow: $1{ }^{\widehat{\gamma}}$ (NMS) ex Araniella [?] cucurbitina, Corylus, coll. 22.ix.1985, coc. (indoors)

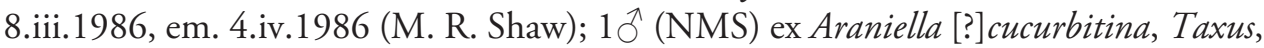

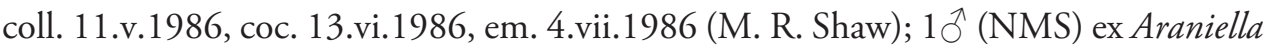
sp., Quercus, Berkshire, Ascot, Silwood Park, coll.29.iv.1994, coc. 30.iv.1994, em. 23.v.1994 (M. R. Shaw); 10 (NMS) ex unspecified spider, Leicestershire, Buddon Wood, coll. 13.vii.2011, em. 2011 (A. Godfrey); 19 (NMS) ex cocoon on Quercus, Northamptonshire, Castor Hanglands, TF 1201, coll. 17.v.2009, em. 16.vii.2009 (M.

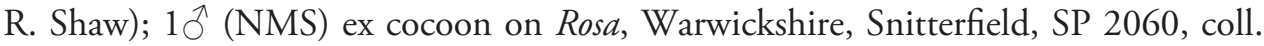
21.v.1988, em. 30.v.1988 (J. Robbins); 1 + (NMS) Huntingdonshire, Monks Wood, Rothamsted light trap 17.viii.2005 (G. R. Broad); ESTONIA: 1 q (RJ) Ösel (Saaremaa), Kaali, 15.viii.1997 (H. Silfverberg).

Distribution. Trans-Palaearctic (Yu et al. 2012), reported as new to Estonia in the present paper.

Biological notes. Koinobiont ectoparasitoid of Araniella spp. (Figures 6-7), mainly on immatures but occasionally on adult specimens, with the only reliable records of host species based on adult hosts or adult specimens collected together with the parasitised specimen seemingly Araniella cucurbitina (Clerck, 1757) (this study) and A. opisthographa (Kulczyn'ski, 1905) (Jones 1988). It overwinters as a minute larva on the host in a position similar to $P$. longa. The cocoon is similar to that of $P$. longa, with no distinctly modified web construction made by the spider prior to death. The species seems to be mostly arboreal (trees and bushes) in a wide range of habitats.

\section{Discussion}

Polysphincta boops and P. longa are among the largest species in the Polysphincta genusgroup in Europe and, based on the specimens we have seen, P. longa exceeds the size of P. boops. Further, with an ovipositor length of 4.3-5.0 mm (based on the reared Polish female and the larger paratype from Azerbaijan), P. longa has a longer ovipositor than any other European species of the Polysphincta genus-group. The two species are morphologically very similar and form a distinct group within the European Polysphincta, characterised by the yellow colour of the scutellum, postscutellum, mandibles, tegulum and subtegular ridge contrasting with the otherwise black body colour (Figure 1). They are also characterised by the very long ovipositor; ovipositor-hind tibia index about 1.7 in both species in this study. They have the submetapleural carina present and complete (this character varies within the genus).

According to the original description (Kasparyan 1976) and the keys in Kasparyan (1981) and Kasparyan and Khalaim (2007), P. longa is distinguished from P. boops by its longer antenna (antennal flagellum longer than front wing in P. longa and shorter 
in $P$. boops), the greater number of antennal flagellomeres (28-33 in $P$. longa and 25-28 in $P$. boops) and the more pubescent mesoscutum. In addition $P$. boops has a slightly shorter malar space $(0.6 \times$ basal mandibular width) than $P$. longa $(0.8 \times$ basal mandibular width).

When we examined the material of $P$. longa and $P$. boops we also found the pubescence of the mesoscutum (Figures 3, 5) and the number of flagellomeres the most useful characters to distinguish the two species. In addition we found that the eye in $P$. longa is a little larger than in $P$. boops, and the shape of the cheeks viewed from in front is different in that they are slightly convex in $P$. longa whereas they are slightly concave in $P$. boops (Figures 2, 4). Further, in $P$. longa, the scape of the antenna is distinctly broader compared to the flagellomeres (Figures 2, 4). According to Kasparyan $(1976,1981)$ and Kasparyan and Khalaim (2007) there seems to be some overlap in the number of flagellomeres between the two species. In our rather limited material there is no overlap between the species when males and females are considered separately. An overlap seems only to exist between the usually larger sex (females) of $P$. boops and the usually smaller sex (males) of $P$. longa. The number of flagellomeres in our material of $P$. boops is 23-27 in males $(\mathrm{n}=17)$ and $26-28$ in females $(\mathrm{n}=7)$, while the number in $P$. longa is $28-31$ in males $(\mathrm{n}=2)$ and $31-33$ in females $(\mathrm{n}=3$; the German female in BMNH has broken antennae). The two largest males of $P$. boops have longer wings (but slightly shorter hind tibia) than the reared male of $P$. longa, and the greater number of flagellomeres in $P$. longa seem thus not a consequence of greater body size alone. In $P$. longa the pubescence of the mesoscutum is moderately dense and covers most of it apart from its posteromedian $0.20-0.25$ (Figure 3 ). In $P$. boops the mesoscutum is mostly bare apart from the anterior part of the median lobe, which is pubescent, and there are also sparse isolated setae on the lateral parts of the lateral lobes of the mesoscutum as well as along the notauli (Figure 5). Taking the observations of Kasparyan into account, the number of flagellomeres should not be used as a single character if they are near 28 , but the combination of the pubescence of the mesoscutum, the number of flagellomeres, and the shape of the cheeks will allow for easy identification of both males and females of $P$. longa.

In our rearing projects $P$. boops has been reared only from Araniella species $(\mathrm{n}=16)$. The only host determined to species level based on the genitalia is a single female $A$. cucurbitina. The single record of A. opisthographa (Jones 1988, Hudson 1988, Fitton et al. 1988) as host species was based on circumstantial evidence, i.e. adult males collected together with the parasitised juvenile specimen (Jones 1988). There is a single rearing record of $P$. boops from Theridion sp. in Brischke (1877), a record frequently referred to (Dalla Torre 1902, Aubert 1969) or apparently cited without reference (Šedivý 1963, Kasparyan 1981, Kolarov 1997). On the basis of what is known about the host specificity of the species of the Polysphincta genus-group (see Shaw 1994, Matsumoto and Takasuka 2010, Fritzén 2010, Fritzén and Fjellberg 2014), we consider such old, aberrant and unrepeated records (in this case from another host family) in the literature to be probably misidentifications of either the parasitoid or the host species. In our projects 14 males and 2 females have been reared successfully. We are unable to explain this odd sex ratio. Taking into account that the two reared females 
also were from Araniella species, the use of a different (and to us unknown) host for fertilized (female) eggs seems extremely unlikely. The only reasons we can think of is that either the species is so rare that females often fail to be mated (in which case they may still lay male-producing eggs), or that female mortality tends to be higher in immature stages, perhaps especially in captivity. However, neither is supported by any evidence in our projects.

The host of $P$. longa has hitherto been unknown. Through beating spruce branches in old forests at Białowieża (Poland) outside the national park in July 2010 the first author obtained only two specimens of $A$. angulatus, and both were parasitised by $P$. longa. In the same forest several juvenile Araneus nordmanni (Thorell, 1870) and also a few $A$. diadematus Clerck, 1757 were seen but were not parasitised. Juveniles of Gibbaranea omoeda (Thorell, 1870) were also numerous in the forests, but this species was not found to be parasitised either. The determination of the juveniles of $A$. angulatus was based on their habitus, including eye size and the light median area on the sternum (which separates the species from Gibbaranea), the dorsal pattern and the ventral marks of the abdomen. The only species in Europe sharing these features and the overall habitus of $A$. angulatus is $A$. circe (Audouin, 1826) (Šestáková et al. 2009), a rare species that hitherto has not been recorded in Poland (van Helsdingen 2013). Although the reared material is small, the results indicate that $P$. longa is not a generalist on Araneidae, and not even on the genus Araneus, but might be restricted to the $A$. angulatus group (Simon 1929), comprising $A$. angulatus, $A$. circe and $A$. grossus (C. L. Koch, 1844) in Europe, or to $A$. angulatus alone. There are no other records of $A$. angulatus as host for any species of the Polysphincta genus-group (Yu et al. 2012).

When collected in July, the larvae on $A$. angulatus were large and they soon killed the spiders and made cocoons. Since $P$. boops and most other Palaearctic species of the Polysphincta group (though not Megaetaira madida (Haliday) (Fitton et al. 1988) and Zatypota maculata Matsumoto and Takasuka (Matsumoto and Takasuka 2010)) overwinter as minute larvae on their hosts (e.g. Fitton et al. 1988, Fritzén 2010, Matsumoto and Takasuka 2010), with the larvae subsequently developing rapidly in spring, this is probably the case with $P$. longa as well. The collection date of the parasitised $A$. angulatus with large larvae indicate a second generation and that $P$. longa is at least bivoltine.

In some species of the Polysphincta genus-group the parasitoid larva manipulates the spider hosts to make different kinds of silk structures for the larva to cocoon in, e.g. "cocoon webs" (sensu Eberhard 2000, see also Nielsen 1923, Matsumoto and Konishi 2007), which are often found in the species attacking orb-weaving spiders. In some species of the Polysphincta genus-group, the spider host spins only a less sophisticated silken structure in the form of a "death chamber" for the parasitoid to cocoon in, prior to being killed by the parasitoid. In these cases, e.g. Polysphincta rufipes (Gravenhorst) on its host Larinioides cornutus (Clerck) (Araneidae), the spider remains will also be found inside the silken chamber (personal observations). In the cases of $P$. longa and $P$. boops the spiders (though orb-weavers) do not make "cocoon webs" or "death chambers" and the spider remains are, at least in vitro, dropped to the bottom of the rearing vial. In the wild, unparasitised specimens of $A$. angulatus and Araniella spp. (the hosts of $P$. longa and $P$. 
boops respectively) do not make any silken retreats, whereas $L$. cornutus usually hides in a silken retreat. Whether the behaviour of making a death chamber, probably induced by the parasitoid larva, invariably correlates with a species-specific use of a silken retreat by the spider needs further study, but we have noted that the remains of Araniella sp. also fall when parasitised by Polysphincta tuberosa Gravenhorst (see also Matsumoto 2009 for a different kind of silken retreat made by a parasitised non orb-weaving spider).

Since the original description (Kasparyan 1976) and the keys in Kasparyan (1981) and Kasparyan and Khalaim (2007) are all in Russian and have been the only publications giving diagnostics for $P$. longa, the species has probably been overlooked in Europe and can presumably be found in entomological collections under $P$. boops. This was the case with the German specimen of P. longa in BMNH (from the Ruthe collection), a specimen originally determined as "P. eximia" (=Zatypota albicoxa (Walker)) but later determined as $P$. boops by Perkins in 1934. This is probably the first specimen of $P$. longa ever collected. During the preparation of the present paper, the first British specimen of $P$. longa was brought to our attention, another specimen originally determined as $P$. boops by its collector. Since $P$. longa would "end up" as $P$. boops with the most commonly used keys in Europe (e.g. Fitton et al. 1988, not treating $P$. longa) we encourage curators of European ichneumonid collections to check the specimens standing as $P$. boops for the characters of $P$. longa. Araneus angulatus, the host of $P$. longa, occurs in most European countries and its parasitoid can therefore be expected to occur in several countries from which it has not yet been reported.

\section{Acknowledgements}

We are grateful to Marzena Stańska and Barbara Patoleta for arranging the necessary permits for the first author for collecting in the Białowieża Forest District, and Societas Entomologica Helsingforsiensis for a grant for the first author to participate in the 18th International congress of arachnology, which made the collecting in Białowieża possible. Jacek Hiszczanski kindly donated several samples of unsorted ichneumonoids to the second author for the NMS collection, and the many donors of reared and other parasitoids are also thanked. Reijo Jussila helped with loan of type specimens, Gavin Broad gave access to the BMNH collection and told us of the British specimen of $P$. longa, and Anna Šestáková commented on the species groups of Araneus.

\section{References}

Aubert JF (1969) Les Ichneumonides ouest-palearctiques et leurs hotes 1. Pimplinae, Xoridinae, Acaenitinae. Laboratoire d'Evolution des Etres Organises, Paris, 1-302.

Brischke CGA (1877) Hymenopterologische Notizen. Deutsche Entomologische Zeitschrift 21: 285-287. 
Dalla Torre CG de (1902) Catalogus Hymenopterorum. Volumen III. Trigonalidae, Megalyridae, Stephanidae, Ichneumonidae, Agriotypidae, Evaniidae, Pelecinidae. Guilelmi Engelmann, Lipsiae, 1901: 1-544, 1902: 545-1141.

Eberhard WG (2000) Spider manipulation by a wasp larva. Nature 406: 255-256. doi: $10.1038 / 35018636$

Fitton MG, Shaw MR, Gauld ID (1988) Pimpline Ichneumon-flies. Hymenoptera, Ichneumonidae (Pimplinae). Handbooks for the Identification of British Insects 7: 1-110.

Fritzén NR (2010) Natural history and description of Zatypota kerstinae sp.nov. (Hymenoptera: Ichneumonidae) reared from Theridion palmgreni Marusik et Tsellarius (Araneae: Theridiidae) in Finland. Zootaxa 2487: 52-60.

Fritzén NR, Fjellberg A (2014) Natural history of Oxyrrhexis zephyrus sp.n. (Hymenoptera: Ichneumonidae), a parasitoid of Enoplognatha serratosignata (Araneae: Theridiidae), with notes on taxonomy and other host species of Oxyrrhexis. Arthropoda Selecta 23: 135-144.

Helsdingen PJ van (2013) Araneae. In: Fauna Europaea Database (Version 2013.1). http:// www.european-arachnology.org

Horstmann K, Floren A (2008) Ichneumonidae (Hymenoptera) from the canopies of primary and managed oak forests in eastern Poland and southern Germany. In: Floren A, Schmidl J (Eds) Canopy arthropod research in Europe. Bioform entomology (Nuremberg), 469-487.

Hudson IR (1988) Some further notes on species of Ichneumonidae reared as ectoparasites of spiders. British Journal of Entomology and Natural History 1: 77-78.

Ivanov K (2002) New faunistic records on family Ichneumonidae (Insecta: Hymenoptera) from Razgradski Heights (NE Bulgaria). Acta Zoologica Bulgarica 54: 35-42.

Jones D (1988) Notes on the spiders of a country estate. British Arachnological Society Newsletter 51: 4-6.

Kasparyan DR (1976) [Review of the Ichneumonids of the tribe Polysphinctini and Poemeniini (Hymenoptera, Ichneumonidae) of the Far East]. Trudy Zoologicheskogo Instituta 67: 68-89. [In Russian]

Kasparyan DR (1981) [A guide to the insects of the European part of the USSR. Hymenoptera, Ichneumonidae. Subfamily Pimplinae (Ephialtinae)]. Opredeliteli Faune SSSR 129: 41-97. [In Russian]

Kasparyan DR, Khalaim AI (2007) [1. Subfamily Pimplinae. In: Lelej AA (Ed.) Key to the insects of Russia Far East. Vol.IV. Neuropteroidea, Mecoptera, Hymenoptera. Pt 5]. Dalnauka, Vladivostok, 279-333. [In Russian]

Kolarov JA (1997) Hymenoptera, Ichneumonidae. Part I. Pimplinae, Xoridinae, Acaenitinae, Collyriinae. Fauna Bulgarica 25: 1-322.

Matsumoto R (2009) “Veils” Against Predators: Modified Web Structure of a Host Spider Induced by an Ichneumonid Parasitoid, Brachyzapus nikkoensis (Uchida) (Hymenoptera). Journal of Insect Behavior 22: 39-48. doi: 10.1007/s10905-008-9152-1

Matsumoto R, Konishi K (2007) Life histories of two ichneumonid parasitoids of Cyclosa octotuberculata (Araneae): Reclinervellus tuberculatus (Uchida) and its new sympatric congener (Hymenoptera: Ichneumonidae: Pimplinae). Entomological Science 10: 267-278. doi: 10.1111/j.1479-8298.2007.00223.x 
Matsumoto R, Takasuka K (2010) A revision of the genus Zatypota Förster of Japan, with descriptions of nine new species and notes on their hosts (Hymenoptera: Ichneumonidae: Pimplinae). Zootaxa 2522: 1-43.

Nielsen E (1923) Contributions to the life history of the Pimpline spider parasites (Polysphincta, Zaglyptus, Tromatobia) (Hym. Ichneum.). Entomologiske Meddelelser 14: 137-205.

Schmidt K, Zmudzinski F (2003) Beitraege zur Kenntnis der badischen Schlupfwespenfauna (Hymenoptera, Ichneumonidae) 2. Pimplinae und Poemeniinae (Pseudorhyssini). Carolinea 60: 131-140.

Šedivý J (1963) Die europäischen Arten der Gattungen Laufeia Tosq., Polysphincta Grav. und Zatypota Foerst. (Hym. Ichneumonidae). Acta Faunistica Entomologica Musei Nationalis Pragae 35: 243-261.

Šestáková A, Krumpál M, Krumpálová Z (2009) Araneidae (Araneae) Strednej Európy. I. Rod Araneus. NOI, Bratislava, 1-150.

Shaw MR (1994) Parasitoid host ranges. In: Hawkins BA, Sheehan W (Eds) Parasitoid community ecology. Oxford University Press, Oxford, 111-144.

Simon E (1929) Les arachnides de France. Le synopsis générale et le catalogue des espèces françaises de l'ordre des Araneae; 3e partie. Paris 6: 533-772.

Walter S (1991) Ichneumonidae (Hymenoptera) in pollution-damaged spruce forests of the Ore mountains. Zoologische Jahrbücher Abteilung für Systematik Ökologie und Geographie der Tiere 118: 449-464.

Yu DS, van Achterberg C, Horstmann K (2012) Taxapad 2012. Ichneumonoidea 2011. Taxonomy, biology, morphology and distribution, online at http://www.taxapad.com 